\title{
Electrochemical and Oxidation Behavior of Yttria Stabilized Zirconia Coating on Zircaloy-4 Synthesized via Sol-Gel Process
}

\author{
S. Rezaee, ${ }^{1}$ Gh. R. Rashed, ${ }^{1}$ and M. A. Golozar ${ }^{2}$ \\ ${ }^{1}$ Department of Technical Inspection Engineering, Petroleum University of Technology (PUT), Abadan Institute of Technology (AIT), \\ P.O. Box 619, Abadan 6318714331, Iran \\ ${ }^{2}$ Department of Material Science Engineering, Isfahan University of Technology (IUT), Isfahan 8415683111, Iran
}

Correspondence should be addressed to S. Rezaee; samanerezaie67@gmail.com

Received 24 April 2013; Revised 23 November 2013; Accepted 25 November 2013

Academic Editor: W. Ke

Copyright $\odot 2013$ S. Rezaee et al. This is an open access article distributed under the Creative Commons Attribution License, which permits unrestricted use, distribution, and reproduction in any medium, provided the original work is properly cited.

Sol-gel 8 wt.\% Yttria Stabilized Zirconia (YSZ) thin films were prepared on zirconium (zircaloy-4 alloy) by dip-coating technique followed by heat treating at various temperatures $\left(200^{\circ} \mathrm{C}, 400^{\circ} \mathrm{C}\right.$, and $\left.700^{\circ} \mathrm{C}\right)$ in order to improve both electrochemical corrosion and high temperature oxidation properties of the substrate. Differential thermal analysis and thermogravimetric analysis (DTATG) revealed the coating formation process. X-ray diffraction (XRD) was used to determine the crystalline phase structure transformation. The morphological characterization of the coatings was carried out using scanning electron microscopy (SEM). The electrochemical behavior of the coated and uncoated samples was investigated by means of open circuit potential, Tafel, and electrochemical impedance spectroscopy (EIS) in a $3.5 \mathrm{wt} . \% \mathrm{NaCl}$ solution. The homogeneity and surface appearance of coatings produced was affected by the heat treatment temperature. According to the corrosion parameters, the YSZ coatings showed a considerable increase in the corrosion resistance, especially at higher heat treatment temperatures. The coating with the best quality, from the surface and corrosion point of view, was subjected to oxidation test in air at $800^{\circ} \mathrm{C}$. The coated sample presented a $25 \%$ reduction in oxidation rate in comparison with bare substrate.

\section{Introduction}

Because of many excellent bulk properties like low thermal neutron capture cross section, favorable mechanical properties and good corrosion resistance even at high temperatures, zirconium and its alloys are widely used in nuclear reactors as fuel cladding and as reactor structural elements, chemical engineering, and lately in biomedical applications. For fuel cladding applications, the alloys of choice are zircaloy-2 (Zr2 ) and zircaloy-4 (Zr-4). In fuel deep geological repository, used fuel bundles and the associated Zr cladding are encapsulated in durable containers and the containers are sealed in an engineered vault at a depth of hundreds of meters in a stable low permeability rock mass. Ground water composition especially in crystalline and sedimentary rock types contains $\mathrm{NaCl}$. In a failed container, zirconium is in contact with $\mathrm{NaCl}$ solution [1-4]. So, they are somehow subject to corrosion and their specific surface properties (e.g., corrosion, oxidation, etc.) should be improved $[2,4]$.

Surface modification of materials permits independent optimization of bulk and surface properties. Among all surface modification techniques such as chemical vapor deposition [5, 6], physical vapor deposition [7], plasma [8], ion implantation $[3,4,9,10]$, and so forth, sol-gel processing has many advantages over other techniques. They include low processing temperature, chemically and physically uniform coatings, high purity, low capital investment, producing thin homogeneous films on large scale, easy controlling of film thickness, and practical in complex geometries effectively [1114].

Many sol-gel derived ceramic thin films like $\mathrm{SiO}_{2}[5,15]$, $\mathrm{ZrO}_{2}[12,16], \mathrm{CeO}_{2}-\mathrm{ZrO}_{2}$ [17], $\mathrm{ZrO}_{2}-\mathrm{SiO}_{2}$ [11], $\mathrm{TiO}_{2}, \mathrm{TiO}_{2}-$ $\mathrm{SiO}_{2}$ [18], and so forth have been produced on different substrates. Zirconia films have been used widely in recent years 
TABLE 1: Chemical composition of zircaloy- 4 .

\begin{tabular}{lccccc}
\hline Element & $\mathrm{Sn}$ & $\mathrm{Fe}$ & $\mathrm{Cr}$ & $\mathrm{Ni}$ & $\mathrm{Zr}$ \\
\hline wt.\% & 1.55 & 0.15 & 0.1 & 0.05 & Bal. \\
\hline
\end{tabular}

$(\mathrm{Fe}+\mathrm{Cr}+\mathrm{Ni}=0.3 \mathrm{wt} . \%)$.

because it possesses more efficient anticorrosion ability, thermal protection, optical properties, easier sol preparation, and good erosion resistance accompanied by toughening strength and its close thermal expansion coefficient to many metals and alloys $[11,14,17]$. Yttria Stabilized Zirconia (YSZ) is the most common system because of its high ionic conductivity and thermal stability offering an improvement in adhesion and corrosion resistance properties [19].

Cracking the film during drying stage is the main concern of sol-gel derived ceramic coatings. In recent years many researchers have tried to reduce these cracks and therefore changed many variables. López et al. [15] have found that the corrosion resistance is improved with increasing the number of deposited silica layers because they become free of cracks and porosities. Domínguez-Crespo et al. [19], Li et al. [20], and López et al. [15] found that denser and more crack-free zirconia and silica films were formed at higher temperatures because of the removal of organic substances. This also helps to increase the anticorrosive properties of the coatings. Baron and Ruiz [21] concluded that the basic catalysts were more effective in crack-free film production compared with acidic catalysts and denser films were produced in more diluted sols. Ugas-Carrión et al. [22] revealed that, by using an optimum acetylacetone concentration as a complexing agent, the porosities and defects of zirconia coatings could be reduced even at low temperatures. Nouri et al. [23] have studied the structural evolution and electrochemical behavior of sol-gel derived zirconia films on 304 stainless steel substrate. The best performance was obtained at $500^{\circ} \mathrm{C}$. At temperatures higher or lower than $500^{\circ} \mathrm{C}$, the coatings properties are reduced.

Considering the above findings with regard to improve in protection against corrosion and high temperature oxidation, the YSZ coating is applied on top of zircaloy-4. In the present work it is focused on the preparation of the stable $8 \mathrm{wt} . \%$ Yttria Stabilized Zirconia sol and sol-gel dip coating using zirconium propoxide/yttrium chloride/acetylacetone/water system and ethanol as a solvent. We describe how Yttria Stabilized Zirconia coating can improve the corrosion and high temperature oxidation resistance of the zircaloy- 4 and the effects of different heat treatment temperature on the coating quality and its corrosion rate will be discussed.

\section{Material and Methods}

2.1. Sol and Coating Preparation. Zircaloy-4 samples were cut in the shape of plates of $20 \mathrm{~mm} \times 10 \mathrm{~mm}$ surface area from a sheet of $1 \mathrm{~mm}$ in thickness. The elemental composition of the zircaloy- 4 is represented in Table 1 . They are subjected to mechanical polishing with sand papers of 120 to 600 grade papers, cleaned in acetone, and then dried under air pressure. Sol of $\mathrm{ZrO}_{2}-8$ wt. $\% \mathrm{Y}_{2} \mathrm{O}_{3}$ was obtained using zirconium (IV) propoxide (70 wt.\% in 1-propanol, Merck), acetylacetone as complexing agent and distilled water in mole ratios of $1: 1: 10$, respectively. Yttrium (III) chloride (99.99\% anhydrous powder) is used as stabilizing agent and ethanol as solvent. The acetylacetone was added to zirconium propoxide to control the reactions; proper quantity of ethanol was well mixed with the previous solution using the magnetic stirrer. Then the precursor solution was added gradually to the proper amount of water while stirring continued. Finally, yttrium (III) chloride was mixed in the solution under continuous stirring. After about 30 minutes a yellow, stable, and transparent precursor sol was obtained. Zirconium concentration in final solution was $0.5 \mathrm{M}$. No precipitate was observed even after 6 months. The zircaloy- 4 substrates were then coated by dip-coating technique with controlled immersion and withdrawal speed of $1 \mathrm{~mm} \cdot \mathrm{s}^{-1}$. The immersion time interval was 3 minutes. After each time of three depositions, the coatings were treated up to $200^{\circ} \mathrm{C}$ with $10^{\circ} \mathrm{C} \cdot \mathrm{min}^{-1}$, and at last, they were heated up to three different temperatures of $200^{\circ} \mathrm{C}, 400^{\circ} \mathrm{C}$, and $700^{\circ} \mathrm{C}$ and then subjected to thermal annealing at that temperature for 1 hour to remove water and organic compounds.

2.2. Characterization. The morphology of the films before electrochemical measurements is studied by Scanning Electron Microscopy (SEM, VEGA, TESCAN-LMU). X-ray diffraction (XRD) (Model Bruker, D8ADVANCE, Germany X-Ray Tube Anode: Cu, Wavelength: $1.5406 \AA(\mathrm{CuK} \alpha)$ ) was used to determine the chemical composition and the crystalline phase structure transformation of the dried gel powder at 3 different temperatures of $150^{\circ} \mathrm{C}, 400^{\circ} \mathrm{C}$, and $700^{\circ} \mathrm{C}$. The crystallite size of the films was determined from the half-height width of the XRD peaks using Scherrer's equation. The process pathway like water or organic substances evaporation and phase transitions were studied by thermal analysis (TG-DTA) (Model L81, 1750, Linseis, Germany) of the samples heated from room temperature to $800^{\circ} \mathrm{C}$ in air at a heating rate of $10^{\circ} \mathrm{C} \cdot \mathrm{min}^{-1}$. Open circuit potential (OCP), electrochemical impedance spectroscopy (EIS), and potentiodynamic polarization tests were done to evaluate the effect of YSZ coatings on the corrosion performance of zircaloy- 4 substrate in $3.5 \mathrm{wt}$.\% aerated $\mathrm{NaCl}$ solution at room temperature. Measurements were done by Autolab device equipped with a computer; Model PGSTAT 302 N. Autolab GPES (general purpose electrochemical system) software was used for evaluating of polarization data in the potential range of $\pm 1.5 \mathrm{~V}$ from OCP after the attainment of steady state at OCP conditions after about 30 minutes. The scan rate used was $0.5 \mathrm{mV} / \mathrm{s}$. The standard electrochemical cell was arranged with saturated $\mathrm{Ag} / \mathrm{AgCl}$ electrode as the reference electrode and platinum as the counter electrode. The exposed area of the samples was $1.8 \mathrm{~cm}^{2}$. Corrosion characteristics such as corrosion potential $\left(E_{\text {corr }}\right)$, corrosion current density $\left(i_{\text {corr }}\right)$, and anodic/cathodic Tafel slopes $\left(\beta_{a}\right.$ and $\left.\beta_{c}\right)$ were obtained from the intersection of cathodic and anodic Tafel curve tangents using Tafel extrapolation method. The polarization resistance $\left(R_{p}\right)$ was determined using Stren-Geary equation (see [24]):

$$
R_{p}=\frac{\beta_{a} \cdot \beta_{c}}{2.303 i_{\text {corr }}}\left(\beta_{a}+\beta_{c}\right)
$$




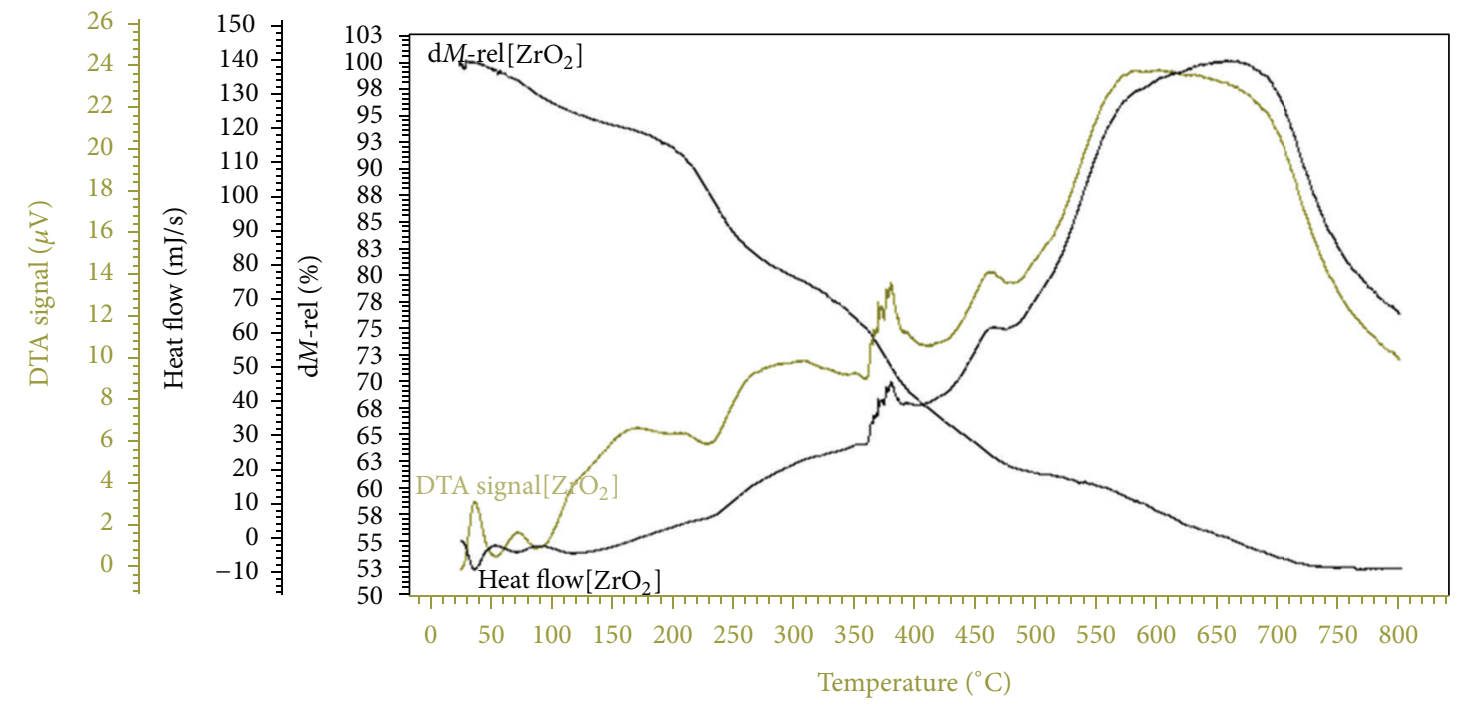

FIGURE 1: Thermal analysis (DTA-TGA) diagram for YSZ powder first dried at $80^{\circ} \mathrm{C}$ for $3 \mathrm{hrs}$ in an oven.

The corrosion rate is calculated using the following equation (see [25]):

$$
r_{\text {corr }}=0.00327 i_{\text {corr }} \frac{M}{n \cdot d},
$$

where $r_{\text {corr }}$ is corrosion rate in millimeter per year (mpy), $n$ is charge number (4), $M$ is molar mass $\left(91.22 \mathrm{~g} \cdot \mathrm{mol}^{-1}\right)$, and $d$ is density of substrate $\left(6.56 \mathrm{~g} \cdot \mathrm{cm}^{-3}\right)$.

The EIS measurements were carried out with FRA2 frequency response analyzer at open circuit potential after $1 \mathrm{hr}$ immersion time with AC amplitude of $20 \mathrm{mV}$ over a frequency range of $100 \mathrm{kHz}$ to $1 \mathrm{mHz}$. Coating thickness was determined using SEM image of the cross section of the coated sample. High temperature oxidation resistance of the coating was evaluated by weight gain test.

\section{Results and Discussion}

3.1. Thermal Analysis Results. Thermal analysis (TGA-DTA) can vividly show what species of gel precursor is removed in each temperature range. Also the temperature that all organic solvents are evaporated and a dense and continuous coating is obtained will be found out by thermal analysis. The YSZ xerogel powder was first dried by $80^{\circ} \mathrm{C}$ for 1.5 hours in an oven and then heated from room temperature to $800^{\circ} \mathrm{C}$ in air at a heating rate of $10^{\circ} \mathrm{C} \cdot \mathrm{min}^{-1}$. As it can be seen from Figure 1, there is a continuous weight reduction in TGA curve during heating up to $730^{\circ} \mathrm{C}$. No more weight loss is observed beyond $730^{\circ} \mathrm{C}$. It is obvious that TGA curve displays three different slopes, and in this regard it could be divided into three different temperature ranges. The first range between $30-180^{\circ} \mathrm{C}$ shows a moderate slope attributing to disappearance of superficial and structural water in gel precursor. The DTA curve in this range shows two small endothermic peaks. One at $50^{\circ} \mathrm{C}$ ascribes to superficial water evaporation and the other one at $90^{\circ} \mathrm{C}$ belongs to structural water removal. The second part on TGA curve starts from $180^{\circ} \mathrm{C}$ to about $480^{\circ} \mathrm{C}$ with a sharp slope due to decomposition of a large amount of organic compounds. Beyond $480^{\circ} \mathrm{C}$, the TGA slope is decreased by $730^{\circ} \mathrm{C}$ and then becomes a horizontal line. Slope reduction of the third temperature range in comparison with the second part asserts that the most amounts of organic species are vanished at $180-480^{\circ} \mathrm{C}$. This behavior is also occurred in YSZ coatings and denser and more crack-free ones are expected at higher temperatures. In other words, the existence of water and organic solvents leads to produce discontinuities and porosities in coatings. The two exothermic peaks in the second temperature range should be considered. The results of works of Tiwari et al. [26] on sol-gel derived YSZ powder revealed that the weight loss between $330^{\circ} \mathrm{C}$ and $450^{\circ} \mathrm{C}$ is due to organic species removal by combustion. Soo et al. [27] ascribed two exothermic peaks near $350^{\circ} \mathrm{C}$ and $421^{\circ} \mathrm{C}$ during zirconia sol-gel derived powders in DTA curve to organic substances decomposition and crystallization of tetragonal structure of zirconia, respectively. The presence of sharp exothermic peak near $380^{\circ} \mathrm{C}$ refers to the crystallization transition of amorphous YSZ gel. XRD pattern in the next section shows that tetragonal phase is produced. As the temperature increases, the tetragonal crystals grow and a wide exothermic peak extending from $550^{\circ} \mathrm{C}$ to $725^{\circ} \mathrm{C}$ is resulted on DTA curve. This crystal growth is also verified by calculating the crystal size using Scherrer's equation in XRD section. Finally, a dense gel powder weighted about $53 \%$ of its initial weight is remained.

3.2. X-Ray Diffraction (XRD). XRD analysis was done to determine which crystallized phases are in the coating at different temperatures. At low temperatures the gel is amorphous. As the temperature increases the amorphous gel transforms to tetragonal phase. Then the crystals of tetragonal phase grow, and at a critical crystal size, tetragonal to monoclinic 


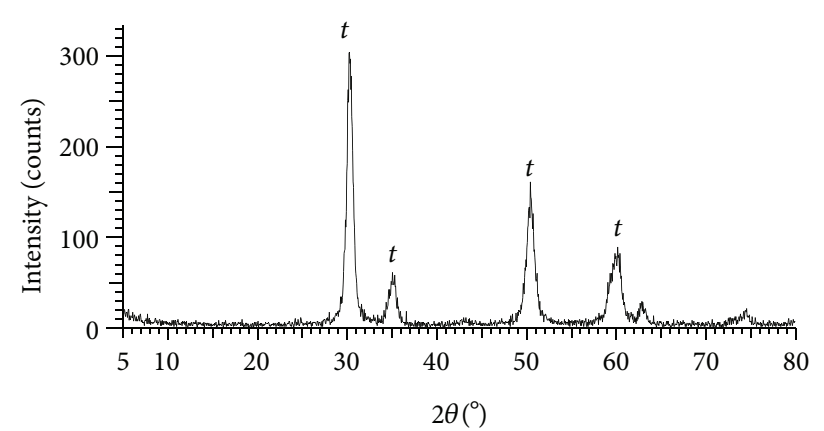

(c)

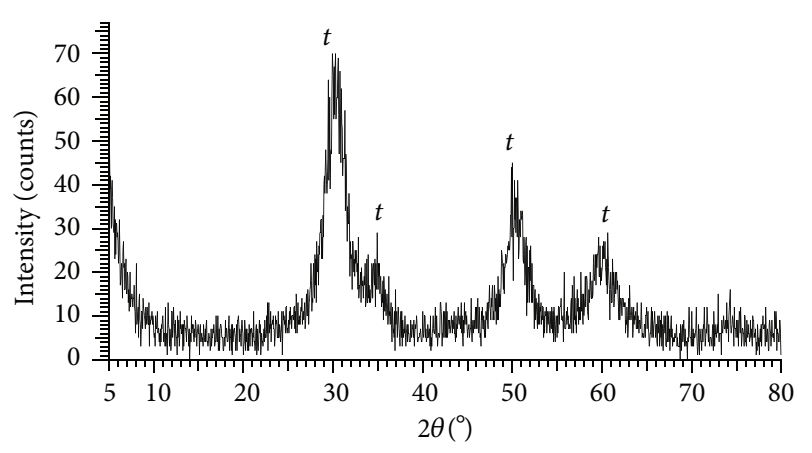

(b)

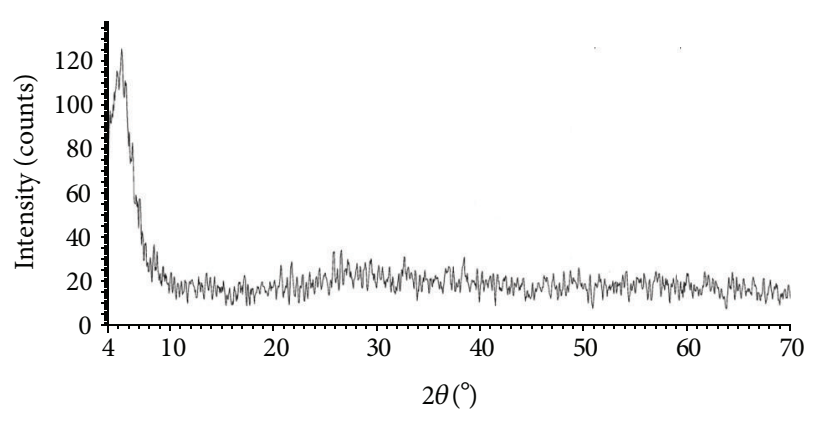

(a)

FIGURE 2: XRD spectra of YSZ powders sintered at (a) $150^{\circ} \mathrm{C}$, (b) $400^{\circ} \mathrm{C}$, and (c) $700^{\circ} \mathrm{C}$. The amorphous to crystalline transformation from $150^{\circ} \mathrm{C}$ to $400^{\circ} \mathrm{C}$ is clearly shown. The intensity of peaks increases from $400^{\circ} \mathrm{C}$ to $700^{\circ} \mathrm{C}$.

phase transformation occurs. This transformation accompanied by a volume expansion which leads to crack emerging $[12,26]$. The previous discussion verifies the importance of phase characterization.

The gel powder was first thermally treated at three different temperatures of $150^{\circ} \mathrm{C}, 400^{\circ} \mathrm{C}$, and $700^{\circ} \mathrm{C}$, then their XRD patterns are obtained. Figure $2(\mathrm{a})$ shows that the samples heated at low temperatures of $150^{\circ} \mathrm{C}$ are amorphous. The gel powder has crystalline structure at higher temperatures of $400^{\circ} \mathrm{C}$ and $700^{\circ} \mathrm{C}$. The crystallization occurs near $400^{\circ} \mathrm{C}$, and according to thermal analysis results, crystallization starts at $380^{\circ} \mathrm{C}$. This indicates that the results of two analyses well satisfy each other. In addition, it is well compatible with other researcher's works revealing the formation of crystallized YSZ above $300^{\circ} \mathrm{C}[19,28,29]$. The patterns of Figures 2(b) and 2(c) belong to tetragonal zirconia crystals and the peaks at $700^{\circ} \mathrm{C}$ are sharper and stronger than $400^{\circ} \mathrm{C}$ due to both remaining of organic compounds and/or small crystal size at lower temperatures. No monoclinic phase was detected up to $700^{\circ} \mathrm{C}$.

The crystal size $(D)$ of YSZ crystals is measured using Scherrer's equation (see $[19,23,26])$ :

$$
D_{\mathrm{hkl}}=\frac{k \lambda}{B \cos \theta},
$$

where $D_{\text {hkl }}$ denotes the average crystallite size of the synthesized YSZ, $k=0.94$ is the shape factor, $\lambda=0.15406 \mathrm{~nm}$ is the $\mathrm{X}$-ray wavelength of $\mathrm{CuK} \alpha, B$ is the full width of the peak measured at half maximum intensity (FWHM) in radians, and $\theta$ represents Bragg's angle of the peak.

The average crystal size of YSZ increases from $5.64 \mathrm{~nm}$ at $400^{\circ} \mathrm{C}$ to $10.22 \mathrm{~nm}$ at $700^{\circ} \mathrm{C}$. This confirms that the wide peak at DTA curve between $550^{\circ} \mathrm{C}$ and $725^{\circ} \mathrm{C}$ is the consequence of crystal growth. In the presence of tetragonal stabilizer of yttria, the critical crystal size of zirconia increases and a higher temperature is needed to monoclinic phase being produced.

3.3. Surface Morphology. The scanning electron micrographs of the coatings heat treated at $200^{\circ} \mathrm{C}, 400^{\circ} \mathrm{C}$, and $700^{\circ} \mathrm{C}$ are shown in Figures 3(a)-3(c). The coatings dried at low temperatures reveal more cracks. As the drying temperature increases, the water and the organic compounds release and the coatings become denser. Li et al. [20] attributed the formation of these cracks to the internal stresses during heat treatment, but they are reduced as the temperature increased. In a sol-gel based coating the gel is made up of a solid network part and connected pores filled with liquid. In the first step of drying, the body shrinks at a constant rate equal to liquid evaporation rate. Due to the capillary forces, the pore sides of the gel are pulled together by the liquid. In the subsequent step, when the gel is too stiff to continue its shrinkage under capillary forces, the interface between liquid and air move into the film. This occurs because the top layers are shrinking quicker than the water and organic substances saturated bottom layers and evaporation is taking place from the liquid/air interface. This produces tensile stresses in the surface layer. It is at this point that cracking will occur. With further increasing in drying temperature, the remaining of organic substances will decompose and a dense and crackfree film is produced. Although such crack formation takes place in most of the films, in the thicker films the shrinkage, evaporation, and decomposition of the bottom layers create more stresses and more cracks $[30,31]$. So it is found that the thickness of YSZ coatings is a crucial factor affecting the corrosion and oxidation behaviors; that is, a multilayer coating is much more effective than the single-layer one. At temperatures higher than tetragonal to monoclinic transformation temperature, the cracks again emerge due to a volume increase in the crystallization transformation. In the presence of stabilizers such as $\mathrm{Y}^{3+}, \mathrm{Ca}^{2+}$, and $\mathrm{Mg}^{2+}$, the transformation temperature shifts to higher values and more liquids are 


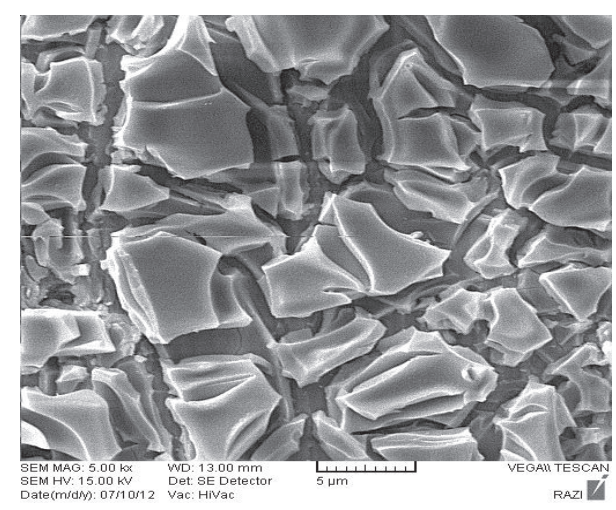

(a)

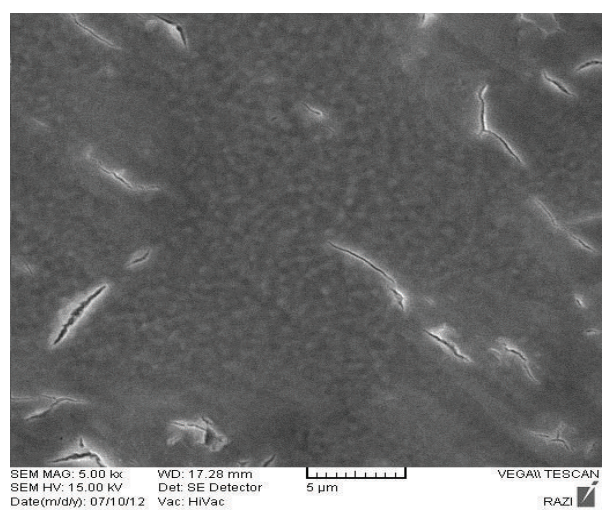

(c)

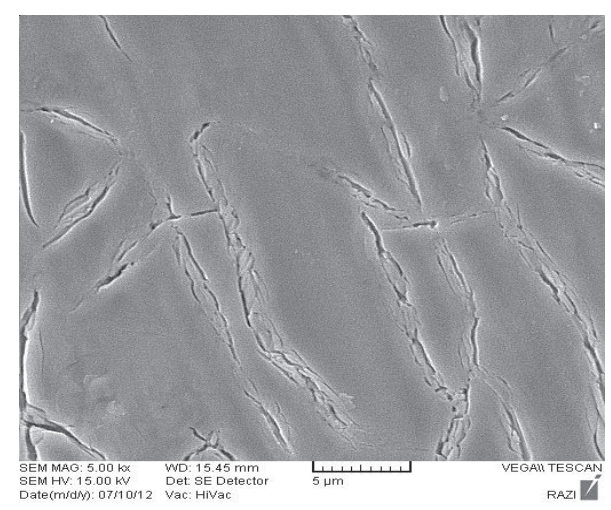

(b)

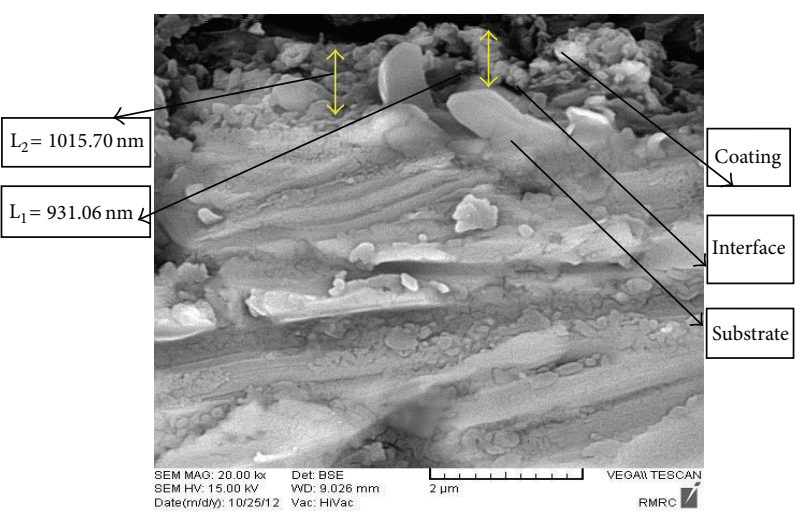

(d)

FIGURE 3: (a)-(c) SEM images of the surface of coated samples with different sintering temperature (a) $200^{\circ} \mathrm{C}$, (b) $400^{\circ} \mathrm{C},(\mathrm{c}) 700^{\circ} \mathrm{C}$, and (d) SEM image of the cross section of coated sample $\left(15\right.$ layers, $\left.700^{\circ} \mathrm{C}\right)$.

extracted and evaporated from the gel without additional volume changes [12, 26].

Domínguez Crespo et al. [19] have also obtained that the cracks of YSZ coatings on commercial carbon steel substrate are decreased due to the removal of organic compounds at higher temperatures.

According to $\mathrm{XRD}$ results, there are no monoclinic phases up to $700^{\circ} \mathrm{C}$ heat treatment due to the presence of $\mathrm{Y}^{3+}$ stabilizer. As it can be seen in Figures 3(a)-3(c), the more crack-free and dense film is obtained at $700^{\circ} \mathrm{C}$.

3.4. Film Thickness. The film thickness of the coatings was determined using SEM image of the cross section of 15 layers coating sintered at $700^{\circ} \mathrm{C}$ (Figure $3(\mathrm{~d})$ ). The total thickness of the coating after 15 deposited layers is about $970 \mathrm{~nm}$. Therefore each layer's thickness would be about $64 \mathrm{~nm}$.

\subsection{Electrochemical Measurements}

3.5.1. Polarization Tests. It can be concluded from the results obtained by Tafel plots (Figure 4) that the YSZ coatings show more noble corrosion potential $\left(E_{\text {corr }}\right)$ and less corrosion current density $\left(i_{\text {corr }}\right)$ when it is dried at higher temperatures.

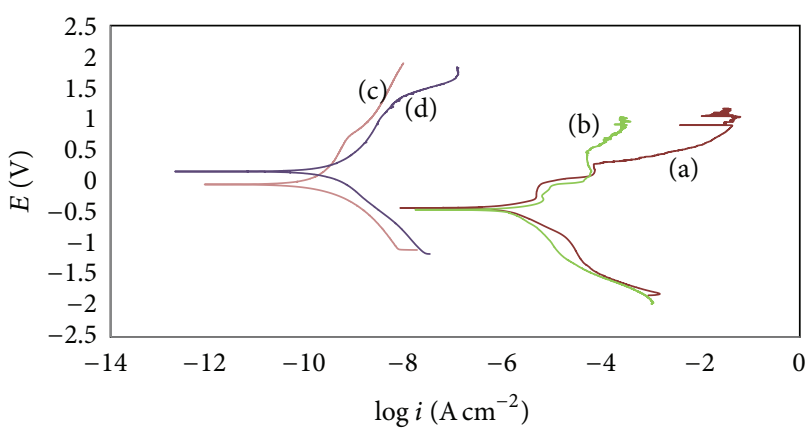

Figure 4: Polarization plots for (a) bare substrate, (b) $200^{\circ} \mathrm{C}$, (c) $400^{\circ} \mathrm{C}$, and (d) $700^{\circ} \mathrm{C}$.

The corrosion current density decreases about $10^{4}$ times and the corrosion potential shifts to positive direction more than $600 \mathrm{mV}$, when the drying temperature increases from $200^{\circ} \mathrm{C}$ to $700^{\circ} \mathrm{C}$. The electrochemical performance of the YSZ coating dried at $200^{\circ} \mathrm{C}$ is even worse than the bare substrate. According to the results of thermal analysis, there are organic substances in the film at $200^{\circ} \mathrm{C}$ and this leads to electrolyte penetration onto the substrate surface. With 
TABLE 2: The electrochemical parameters of coated and uncoated samples for different sintering temperature.

\begin{tabular}{lcccccc}
\hline Sintering temp. $\left({ }^{\circ} \mathrm{C}\right)$ & $i_{\text {corr }}\left(\mathrm{A} \cdot \mathrm{cm}^{-2}\right)$ & $E_{\text {corr }}(\mathrm{V})$ & $\beta_{a}(\mathrm{~V} / \mathrm{dec})$ & $\beta_{c}(\mathrm{~V} / \mathrm{dec})$ & $R_{p}\left(\mathrm{ohm} \cdot \mathrm{cm}^{2}\right)$ & $\mathrm{Corr} . \mathrm{rate}\left(\mathrm{mm} \cdot \mathrm{yr}^{-1}\right)$ \\
\hline Bare & $9.80 E-07$ & -0.41 & 0.035 & 0.05 & $1.60 E+3$ & $7.35 E-3$ \\
200 & $2.47 E-07$ & -0.44 & 0.070 & 0.03 & $2.62 E+3$ & $2.91 E-3$ \\
400 & $1.21 E-10$ & -0.05 & 0.050 & 0.04 & $7.49 E+6$ & $7.20 E-8$ \\
700 & $9.76 E-11$ & 0.21 & 0.035 & 0.05 & $9.33 E+7$ & $6.68 E-8$ \\
\hline
\end{tabular}

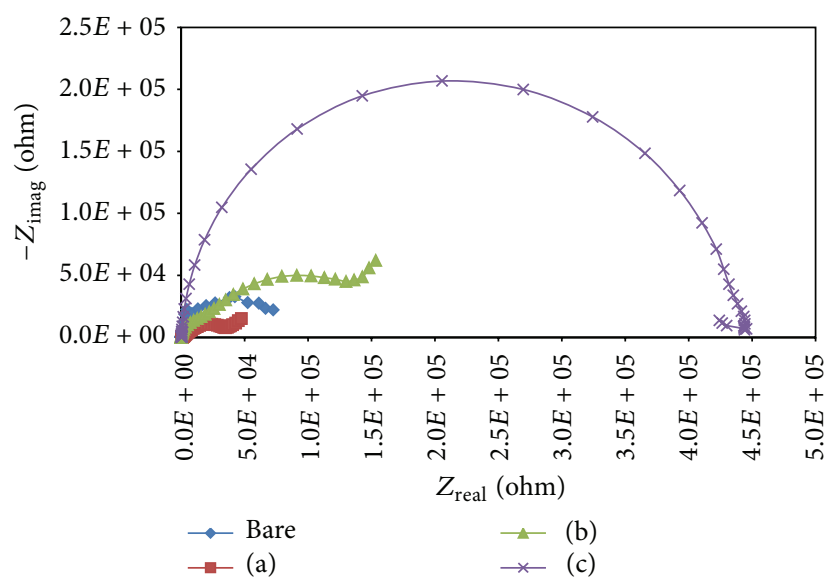

Figure 5: Nyquist plots for bare and coated samples dried at (a) $200^{\circ} \mathrm{C}$ (b) $400^{\circ} \mathrm{C}$, and (c) $700^{\circ} \mathrm{C}$, after 1 hour immersion in $3.5 \mathrm{wt} . \%$ $\mathrm{NaCl}$ electrolyte.

increasing temperature the organic substances evaporation and decomposition increase the densification of the films.

López et al. have also concluded that the corrosion resistance of high temperature treatment silica layers produced by sol-gel process is better than the low temperature heat treated ones. Li et al. [20] attributed the lower corrosion resistance of zirconia coating on magnesium substrate at the low temperature in comparison with the high temperature, to the poor adhesion between the substrate and the zirconia coating. The electrochemical parameters of coated and uncoated samples for different drying temperature are reported in Table 2.

3.5.2. Electrochemical Impedance Spectroscopy (EIS). Figure 5 shows the Nyquist plot representation of the electrochemical impedance measurements carried out in $3.5 \mathrm{wt} . \% \mathrm{NaCl}$ solution for bare and coated samples at three different drying temperatures of $200^{\circ} \mathrm{C}, 400^{\circ} \mathrm{C}$, and $700^{\circ} \mathrm{C}$ after about 1 hour immersion in order to obtain the evolution of the coating's protective properties, also their corrosion mechanism.

It is possible to observe that the real part of impedance ( $X$-axis) at low frequency is strongly increased with drying temperature. Since the real part of impedance at low frequency can be considered equal to the resistance correlated to the Faradic processes, this observation evidences that the barrier property tends to be increased as a function of drying temperature.
The impedance spectra for Nyquist diagrams were analyzed by fitting the experimental data to equivalent circuit model in Figure 6 by Zsim software. Figure 6(a) simulates the bare and coated samples dried at $700^{\circ} \mathrm{C}$ and Figure 6(b) was used for coated samples dried at $200^{\circ} \mathrm{C}$ and $400^{\circ} \mathrm{C}$. In the equivalent circuits, $R_{s}$ is the solution resistance, $R_{\mathrm{ct}}$ is the charge transfer resistance, $\mathrm{CPE}_{\mathrm{dl}}$ is the double layer capacitance, and $\mathrm{CPE}_{\text {coat }}$ models the intact layer, while the resistance $R_{p}$ is associated to large pores in the outer layer. The intermediate oxide is modeled with the constant phase element $\left(\mathrm{CPE}_{\mathrm{ox}}\right)$ and the resistance $R_{\mathrm{ox}}$. CPE $\mathrm{Ox}_{\mathrm{ox}}$ describes a network of electrolyte resistances and double layer capacitors in the pores of the layer, while $R_{\mathrm{ox}}$ is related to the barrier properties of the film. The parameter $R_{\mathrm{ox}}$ is affected by nanopores in this layer. Therefore, this is the most important parameter of the equivalent circuit of Figure 6(b) as long as corrosion protection is concerned. In general, the charge transfer resistance could be compared in all cases to evaluate their corrosion performance. Here, a constant phase element (CPE) is commonly used to represent capacitance because it is hardly pure capacitance in the real electrochemical process [17].

Parameters obtained from EIS tests are presented in Table 3. Heat treatment at higher temperatures improves the coating resistance. This observation is well compatible with the Tafel results and again confirms that, at higher temperatures, the organic substances decompose more than lower temperatures and this leads to more densification of the coating.

3.6. High Temperature Corrosion (Oxidation Resistance). According to the SEM results, the most homogeneous and crack-free coating was obtained at $700^{\circ} \mathrm{C}$. This sample was subjected to weight gain test in air at $800^{\circ} \mathrm{C}$ for 110 minutes to evaluate YSZ coating resistance against high temperature oxidation. Figure 7 shows the weight gain versus time curve of both bare and coated samples. This coating reduces the oxidation rate of coated zircaloy- 4 about $25 \%$ when compared with the bare substrate. So the YSZ coating acts as a thermal barrier allowing the use of this kind of material at higher operational temperatures. Li et al. [32] have investigated high temperature oxidation of bare mild steel and $\mathrm{ZrO}_{2}$ coated samples in air at $450-550^{\circ} \mathrm{C}$ for 12 hours. They concluded that the oxidation resistance of mild steel at this temperature is about 6.5 times higher than that of uncoated substrates. Baron and Ruiz [21] have found that high temperature oxidation of $1.25 \mathrm{Cr}-0.5 \mathrm{Mo}$ steel is reduced in the presence of YSZ 


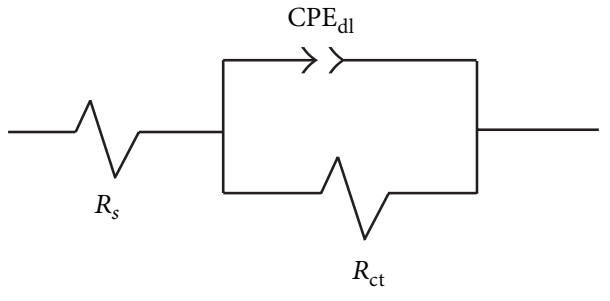

(a)

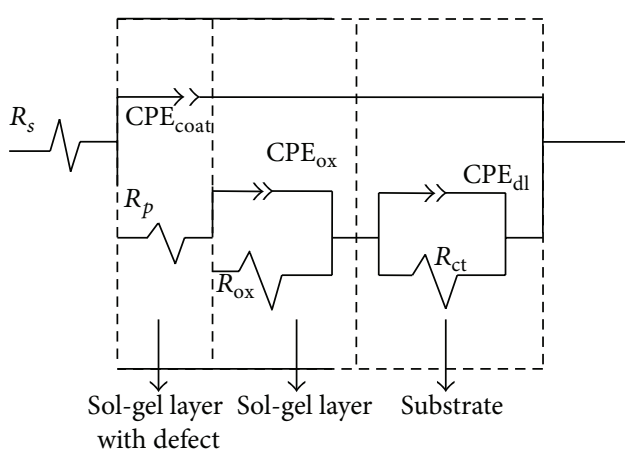

(b)

FIGURE 6: Equivalent circuits of samples after 1 hour immersion in $3.5 \mathrm{wt} . \% \mathrm{NaCl}$ electrolyte: (a) bare and coated one dried at $700^{\circ} \mathrm{C}$ and (b) coated and dried at $200^{\circ} \mathrm{C}$ and $400^{\circ} \mathrm{C}$.

TABle 3: Parameters of equivalent electrical circuit for sol-gel coated samples immersed in $3.5 \mathrm{wt} . \% \mathrm{NaCl}$ electrolyte.

\begin{tabular}{lcccccc}
\hline Sample & \multirow{2}{*}{$R_{s}\left(\Omega \mathrm{cm}^{2}\right)$} & $Y_{0}\left(\mathrm{~F} \cdot \mathrm{cm}^{2}\right)$ & $n$ & $R_{\mathrm{ox}}\left(\Omega \mathrm{cm}^{2}\right)$ & $R_{\mathrm{ct}}\left(\Omega \mathrm{cm}^{2}\right)$ & $Y_{0}\left(\mathrm{~F} \cdot \mathrm{cm}^{2}\right)$ \\
\hline Bare & 32 & - & - & - & $1.68 E+5$ & $3.00 E-6$ \\
$\mathrm{a}$ & 16 & $2.00 E-4$ & 0.98 & $1.00 E+5$ & 902 & $8.20 E-6$ \\
$\mathrm{~b}$ & 21 & $1.00 E-9$ & 0.93 & $6.3 E+7$ & $1.90 E+5$ & $5.40 E-9$ \\
$\mathrm{c}$ & 27 & - & - & - & $1.90 E+8$ & 0.52 \\
\hline
\end{tabular}

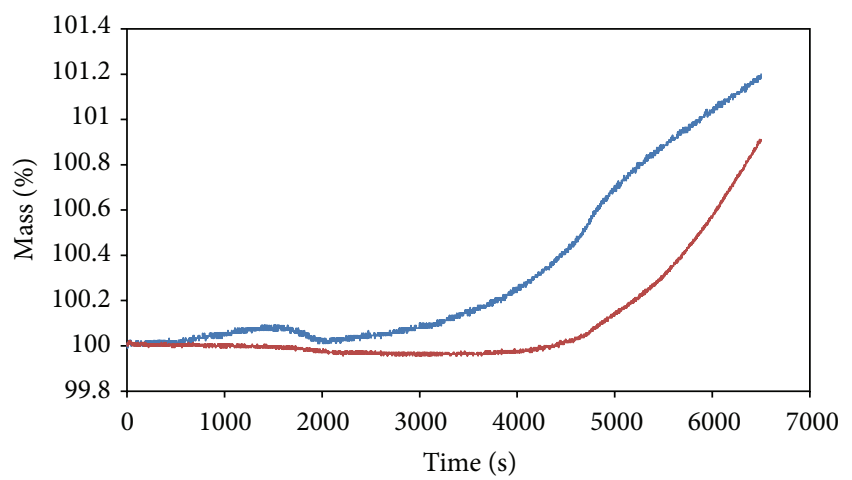

(a)

$-(\mathrm{b})$

FIGURE 7: Weight gain versus time curves for (a) bare and (b) coated zircaloy- 4 exposed to air at $800^{\circ} \mathrm{C}$.

coating. This oxidation reduction was about $35 \%$ when the sol is prepared with acidic catalyst, and it is $62 \%$ with a basic catalyst during 96 hours at $700^{\circ} \mathrm{C}$ in air. The proposed mechanism was that the YSZ coating acts as a physical barrier making outward diffusion of iron difficult. However, once the stresses generated by the slow growing oxides break the continuity of the coating, the formation of vacancies-cations pair (the $\mathrm{Zr}^{4+}$ cations react with the growing iron oxides forming pairs with vacancies) keeps the oxidation rate lower than for uncoated samples. Such mechanism can be expected in the application of YSZ coating on the zircaloy-4 substrate.

\section{Conclusion}

The present study shows that in the presence of yttria cations, the tetragonal phase in sol-gel YSZ coating can be stabilized even at $700^{\circ} \mathrm{C}$. This stabilization prevents from tetragonal to monoclinic transformation and the crack formation resulting from volume expansion is not occurred. The surface quality and corrosion properties of the coatings strongly depend on the heat treatment temperature, because the process requires the condensation reaction and densification among the sols, which affects the diffusion of electrolytes at the metal/solution interface through coating. The higher corrosion protection was achieved with drying at $700^{\circ} \mathrm{C}$. This coating also reduces the oxidation rate of the zircaloy- 4 in about $25 \%$ when compared with the bare substrate.

\section{References}

[1] Y. Chen, M. Urquidi-Macdonald, and D. D. Macdonald, “The electrochemistry of zirconium in aqueous solutions at elevated temperatures and pressures," Journal of Nuclear Materials, vol. 348, no. 1-2, pp. 133-147, 2006.

[2] D. W. Shoesmith and D. Zagidulin, "The corrosion of zirconium under deep geologic repository conditions," Journal of Nuclear Materials, vol. 418, no. 1-3, pp. 292-306, 2011.

[3] D. Q. Peng, X. D. Bai, X. W. Chen et al., "Corrosion behavior of tin ions implanted zirconium in $1 \mathrm{~N}_{2} \mathrm{SO}_{4}$," Applied Surface Science, vol. 239, no. 3-4, pp. 342-352, 2005.

[4] D. Q. Peng, X. D. Bai, X. W. Chen, Q. G. Zhou, X. Y. Liu, and P. Y. Deng, "Comparison of aqueous corrosion behavior of zirconium and zircaloy-4 implanted with molybdenum," Nuclear Instruments and Methods in Physics Research B, vol. 211, no. 1, pp. 55-68, 2003. 
[5] L. Cadoret, N. Reuge, S. Pannala et al., "Silicon chemical vapor deposition on macro and submicron powders in a fluidized bed," Powder Technology, vol. 190, no. 1-2, pp. 185-191, 2009.

[6] M. Brunet, H. M. Kotb, L. Bouscayrol et al., "Nanocrystallized tetragonal metastable $\mathrm{ZrO}_{2}$ thin films deposited by metalorganic chemical vapor deposition for 3D capacitors," Thin Solid Films, vol. 519, no. 16, pp. 5638-5644, 2011.

[7] C. Giolli, F. Borgioli, A. Credi et al., "Characterization of $\mathrm{TiO}_{2}$ coatings prepared by a modified electric arc-physical vapour deposition system," Surface and Coatings Technology, vol. 202, no. 1, pp. 13-22, 2007.

[8] W. Xue, Q. Zhu, Q. Jin, and M. Hua, "Characterization of ceramic coatings fabricated on zirconium alloy by plasma electrolytic oxidation in silicate electrolyte," Materials Chemistry and Physics, vol. 120, no. 2-3, pp. 656-660, 2010.

[9] D. Q. Peng, X. D. Bai, and B. S. Chen, "Surface analysis and corrosion behavior of zirconium samples implanted with yttrium and lanthanum," Surface and Coatings Technology, vol. 190, no. 2-3, pp. 440-447, 2005.

[10] D. Q. Peng, X. D. Bai, X. W. Chen, Q. G. Zhou, X. Y. Liu, and R. H. Yu, "Corrosion behavior in $1 \mathrm{~N} \mathrm{H}_{2} \mathrm{SO}_{4}$ of zirconium ion implanted with nickel," Surface and Coatings Technology, vol. 187, no. 2-3, pp. 300-306, 2004.

[11] P. Kiruthika, R. Subasri, A. Jyothirmayi, K. Sarvani, and N. Y. Hebalkar, "Effect of plasma surface treatment on mechanical and corrosion protection properties of UV-curable sol-gel based GPTS- $\mathrm{ZrO}_{2}$ coatings on mild steel," Surface and Coatings Technology, vol. 204, no. 8, pp. 1270-1276, 2010.

[12] W. Liu, Y. Chen, C. Ye, and P. Zhang, "Preparation and characterization of doped sol-gel zirconia films," Ceramics International, vol. 28, no. 4, pp. 349-354, 2002.

[13] A. Díaz-Parralejo, A. Macías-García, J. Sánchez-González, M. Á. Díaz-Díez, and E. M. Cuerda-Correa, "Influence of the experimental parameters on the synthesis process of yttriadoped zirconia sol-gel films," Surface and Coatings Technology, vol. 204, no. 14, pp. 2257-2261, 2010.

[14] M. A. D. Crespo, A. G. Murillo, A. M. Torres-Huerta, C. Yañez-Zamora., and F. D. J. Carrillo-Romo, "Electrochemical behaviour of ceramic yttria stabilized zirconia on carbon steel synthesized via sol-gel process," Journal of Alloys and Compounds, vol. 483, no. 1-2, pp. 437-441, 2009.

[15] A. J. López, J. Rams, and A. Ureña, "Sol-gel coatings of low sintering temperature for corrosion protection of ZE41 magnesium alloy," Surface and Coatings Technology, vol. 205, no. 17-18, pp. 4183-4191, 2011.

[16] N. N. Voevodin, N. T. Grebasch, W. S. Soto et al., "An organically modified zirconate film as a corrosion-resistant treatment for aluminum 2024-T3," Progress in Organic Coatings, vol. 41, no. 4, pp. 287-293, 2001.

[17] L. Paussa, N. C. Rosero Navarro, D. Bravin et al., " $\mathrm{ZrO}_{2}$ solgel pre-treatments doped with cerium nitrate for the corrosion protection of AA6060," Progress in Organic Coatings, vol. 74, no. 2, pp. 311-319, 2012.

[18] M. Jokinen, M. Patsi, H. Rahiala, T. Peltola, M. Ritala, and J. B. Rosenholm, "Influence of sol and surface properties on in vitro bioactivity of sol-gel-derived $\mathrm{TiO}_{2}$ and $\mathrm{TiO}_{2}-\mathrm{SiO}_{2}$ films deposited by dip-coating method," Journal of Biomedical Materials Research A, vol. 42, no. 2, pp. 295-302, 1998.
[19] M. A. Domínguez-Crespo, A. García-Murillo, A. M. TorresHuerta, F. J. Carrillo-Romo, E. Onofre-Bustamante, and C. Yáñez-Zamora, "Characterization of ceramic sol-gel coatings as an alternative chemical conversion treatment on commercial carbon steel," Electrochimica Acta, vol. 54, no. 10, pp. 2932-2940, 2009.

[20] Q. Li, X. Zhong, J. Hu, and W. Kang, "Preparation and corrosion resistance studies of zirconia coating on fluorinated AZ91D magnesium alloy," Progress in Organic Coatings, vol. 63, no. 2, pp. 222-227, 2008.

[21] Y. S. Baron and A. Ruiz, "Sol-gel coating to reduce $1.25 \mathrm{Cr}$ 0.5 Mo steel oxidation at $700^{\circ} \mathrm{C}$ : catalyst type effect," Corrosion Science, vol. 53, no. 3, pp. 1060-1065, 2011.

[22] R. Ugas-Carrión, F. Sittner, C. J. Ochs, S. Flege, and W. Ensinger, "Characterization of the porosity of thin zirconium oxide coatings prepared at low temperatures," Thin Solid Films, vol. 517, no. 6, pp. 1967-1969, 2009.

[23] E. Nouri, M. Shahmiri, H. R. Rezaie, and F. Talayian, "A comparative study of heat treatment temperature influence on the thickness of zirconia sol-gel thin films by three different techniques: SWE, SEM and AFM," Surface and Coatings Technology, vol. 206, no. 19-20, pp. 3809-3815, 2012.

[24] P. C. R. Varma, B. Duffy, and J. Cassidy, "Influence of magnesium nitrate on the corrosion performance of sol-gel coated AA2024-T3 aluminium alloy," Surface and Coatings Technology, vol. 204, no. 3, pp. 277-284, 2009.

[25] M. G. Fontana, Corrosion Engineering, McGraw-Hill, Singapore, 1986.

[26] S. K. Tiwari, J. Adhikary, T. B. Singh, and R. Singh, "Preparation and characterization of sol-gel derived yttria doped zirconia coatings on AISI 316L," Thin Solid Films, vol. 517, no. 16, pp. 4502-4508, 2009.

[27] M. T. Soo, N. Prastomo, A. Matsuda et al., "Elaboration and characterization of sol-gel derived $\mathrm{ZrO}_{2}$ thin films treated with hot water," Applied Surface Science, vol. 258, no. 13, pp. 5250$5258,2012$.

[28] E. Nouri, M. Shahmiri, H. R. Rezaie, and F. Talayian, "Investigation of structural evolution and electrochemical behaviour of zirconia thin films on the 316L stainless steel substrate formed via sol-gel process," Surface and Coatings Technology, vol. 205, no. 21-22, pp. 5109-5115, 2011.

[29] Q. Li, B. Chen, S. Xu, H. Gao, L. Zhang, and C. Liu, "Structural and electrochemical behavior of sol-gel $\mathrm{ZrO}_{2}$ ceramic film on chemically pre-treated AZ91D magnesium alloy," Journal of Alloys and Compounds, vol. 478, no. 1-2, pp. 544-549, 2009.

[30] A. E. Markowitz, Optimization of sol-gel composite films through chemical and thermal processing [M.S. thesis], Queen's University, Ontario, Canada, 1998.

[31] H. Kozuka and M. Kajimura, "Single-step dip coating of crackfree $\mathrm{BaTiO}_{3}$ films $>1 \mu \mathrm{m}$ thick: effect of poly (vinylpyrrolidone) on critical thickness," Journal of the American Ceramic Society, vol. 83, no. 5, pp. 1056-1062, 2000.

[32] H. Li, K. Liang, L. Mei, S. Gu, and S. Wang, "Oxidation protection of mild steel by zirconia sol-gel coatings," Materials Letters, vol. 51, no. 4, pp. 320-324, 2001. 

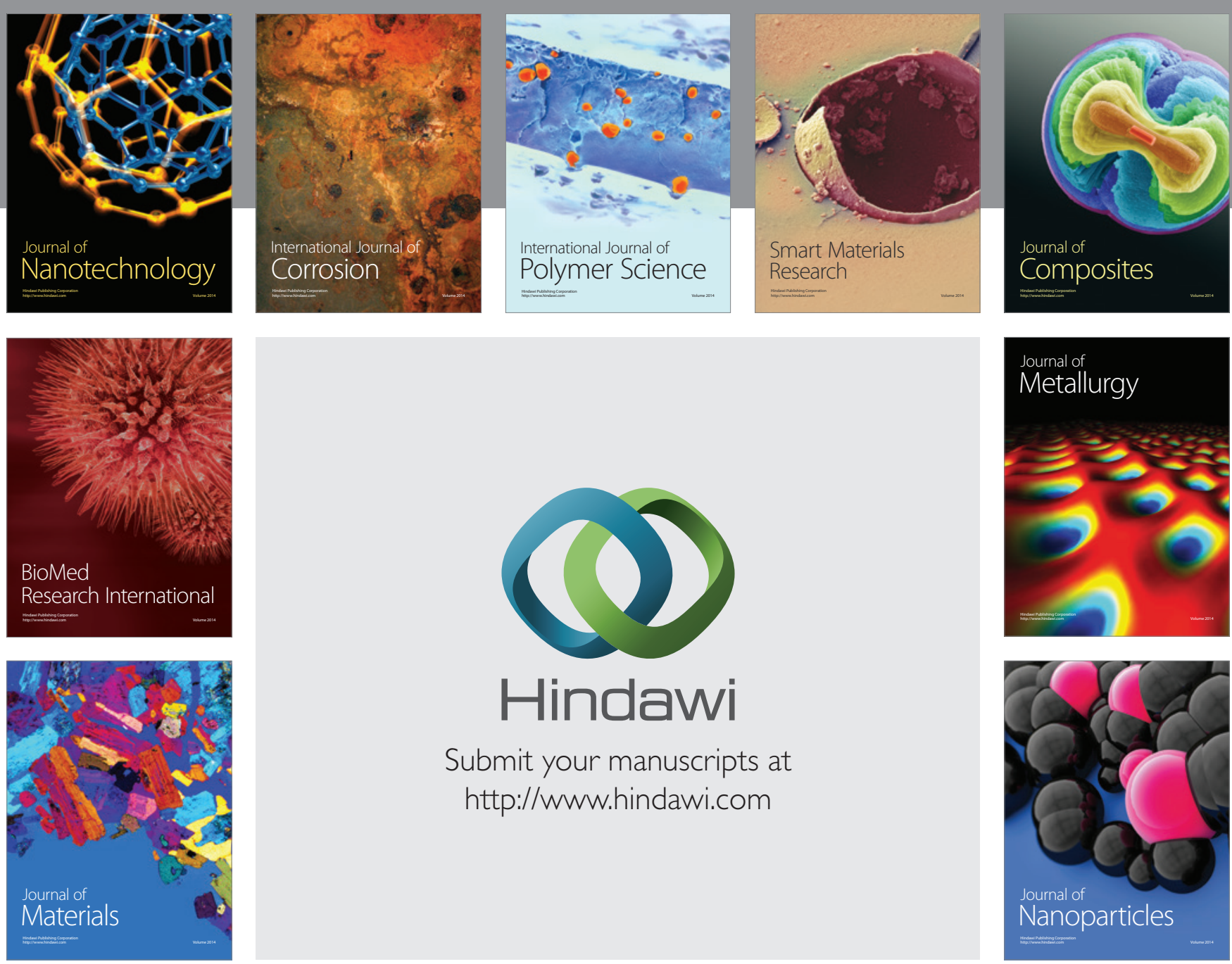

Submit your manuscripts at http://www.hindawi.com
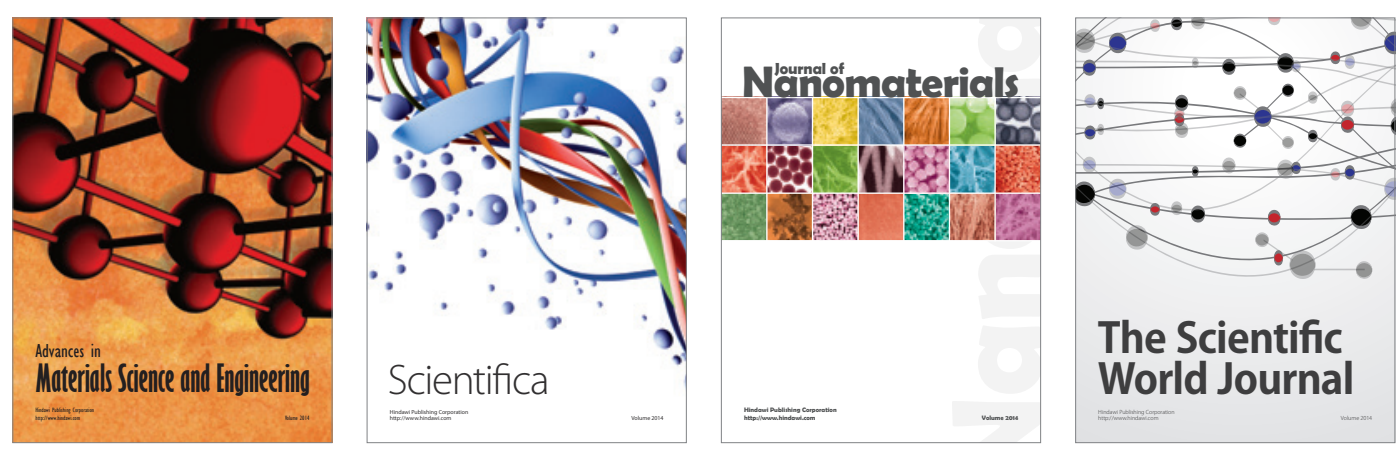

\section{The Scientific World Journal}
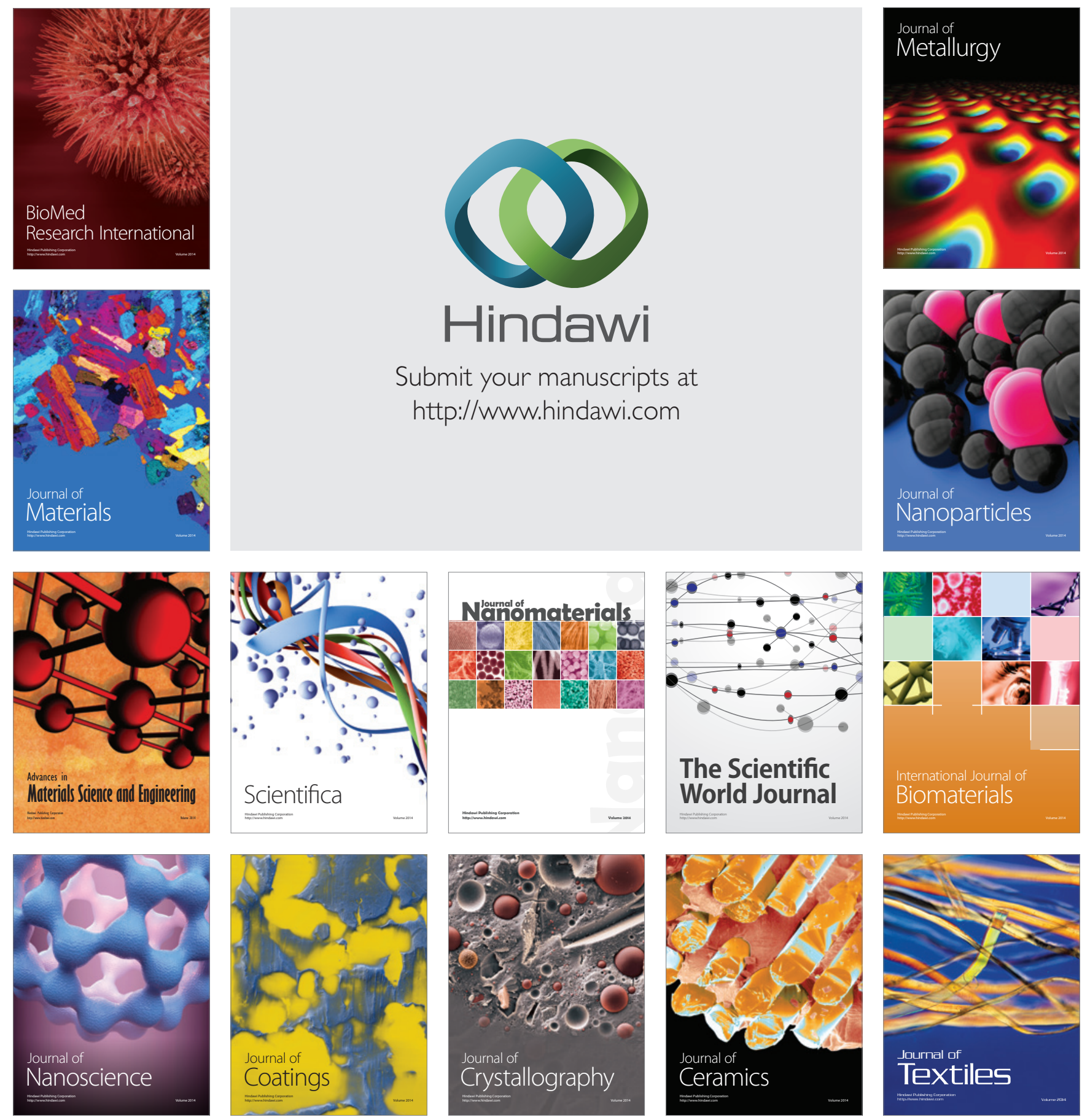